ISSN: 2146-3042

DOI: $10.25095 /$ mufad.510669

\title{
Çimento Sektörü Açısından Sistematik Risk - Finansal Oran İlişkisi: Ana Çimento Üreticisi Ülkeler Karşılaştırması
}

\author{
Umut UYAR* \\ Emin ÇAĞLAK ${ }^{* *}$
}

\section{ÖZET}

Halka açık olmayan firmalar için öz kaynak maliyeti hesaplanması, uzun yıllardır finans literatüründe gündemde olan bir konudur. Özellikle organize bir piyasada işlem görmeyen firmalar için sistematik risk değişkeninin hesaplanma zorluğu, konunun odak noktasını oluşturmaktadır. Muhasebe Betası, problemin çözümü için geliştirilmiş bir teknik olmakla birlikte, yapılan çalışmalarda sektörden sektöre, piyasadan piyasaya modellemenin değişiyor olması bu çalışmanın motivasyonunu olușturmaktadır. Çalıșmanın temel amacl, çimento sektöründe farklı ülkelerde faaliyet gösteren halka açık firmaların mali tablo verileri ile sistematik risk göstergesi olan finansal beta katsaylları arasindaki ilișkinin tespit edilmesidir. Bu amaçla, sektörde dünya lideri olan Türkiye ve Diğer Ülkelerde faaliyet gösteren firmaların 2007-2017 yılları arasındaki çeyreklik muhasebe temelli değişkenleri ile hesaplanan finansal beta katsayları panel veri analizine tabi tutulmuştur. Elde edilen bulgulara göre, aynı sektörde faaliyet gösterseler dahi beta ile ilişkili finansal değişkenler Türkiye ve diğer ülkeler açısından farklılaşabilmektedir. Çalışma sonuçları, teorik beklentilerle açılanabilmekte ve literatürdeki birçok çalışma ile paralellik arz etmektedir. Aynı sektörün farklı ülke grupları açısından incelenmesi yönünden özgünlük taşımaktadır.
\end{abstract}

Anahtar Kelimeler: Muhasebe Betası, Sistematik Risk, Çimento Sektörü

JEL Sinıflandırması: G10, G30, G32

\section{Systematic Risk - Financial Ratios Relationship Based On Cement Industry: The} Comparison Of Main Cement Manufacturer Countries

\section{ABSTRACT}

It has been a hot topic for many years in finance literature that to the calculation of the cost of equity for nonpublicly traded companies. The source of the problem that it is hard to estimate the systematic risk coefficient for that kind of firms. Accounting Beta is suggested for the solution of the problem. However, the calculation model could be varying industry to industry or market to market. The main purpose of study that to investigate the relationship between systematic risk and financial statement data for cement firms in terms of different countries. Firms from Turkey and firms from the other manufacturer countries' financial statements data and financial beta coefficients are used with panel data analysis for the period of 2007Q3 - 2017Q3. The results show that the relationship between financial beta and accounting based data could be differing from the point of countries, though all firms operate in the same sector. The estimation results are parallel with lots of former research and also in accordance with theoretical expectations.

Keywords: Accounting Beta, Systematic Risk, Cement Industry

Jel Classification: G10, G30, G32

\footnotetext{
${ }^{*}$ Dr. Öğr. Üyesi, Pamukkale Üniversitesi, İktisadi ve İdari Bilimler Fakültesi, uuyar@ pau.edu.tr, ORCID ID: 0000-0001-6217-8283

** Öğr. Gör., Afyon Kocatepe Üniversitesi, Başmakçı Meslek Yüksekokulu, ecaglak@aku.edu.tr, ORCID ID: 0000-0003-2798-7450
} 


\section{GíRiș}

Hayatın her noktasında var olan risk ile firmalar küresel ekonomide yüz yüze gelmektedir. Firmalar için risk ve getiri kavramları birlikte var olmaktadır ve getiri maksimizasyonu risk tarafindan baskılanmaktadır. Bu risk faktörü finansal açıdan beta kavramı ile ifade edilebilmektedir. Beta, bir finansal varlığın veya portföyün, sistematik riskini göstermekte ve piyasa getirisine olan duyarlılığını ölçmek için kullanılmaktadır. Beta bir katsayı olarak, Sermaye Varlıkların Fiyatlama Modeli (SVFM) kullanılarak tahmin edilebilmektedir. Tahmin edilen finansal betanın, 1'den yüksek olması, söz konusu varllğın getirisinin piyasa getirisi bir birim artarken daha yüksek değerde arttı̆ını; 1'e eşit olması piyasa getirisi ile beraber hareket ettiğini göstermektedir. Finansal beta katsayısının 1 değerinden daha düşük olması durumu ise ilgili varlık getirisinin piyasa getirisinin bir birimlik hareketine daha düşük değerlerle cevap verdiğini ifade etmektedir. Yüksek finansal beta değeri yüksek volatiliteyi ifade ederken, dolaysıyla riskin de yüksek olduğuna işaret etmektedir.

Firmaların kaynak maliyetinin hesaplanabilmesi için Ağılıklı Ortalama Sermaye Maliyeti (AOSM) literatürde kanıtlanmış bir yöntemdir. AOSM, firmaların kaynak yapısı içerisinde kullandıkları yabancı ve öz kaynaklarının maliyetlerinden oluşmaktadır. Yöntemde kaynak kalemleri maliyetleri göz önüne alınarak her bir kaynağın maliyeti, toplam kaynaklar içindeki yüzdesi ile çarpılarak ağırlıklı ortalama kaynak maliyeti hesaplanmaktadır. Bu hesaplamada yabancı kaynakların (kısa-uzun vade) maliyeti, firmaların ödediği faiz oranı kullanılarak kolaylıkla hesaplanabilir. Öz kaynak maliyetinin hesaplanması ise çok-faktörlü modeller dâhilinde veya SVFM modeli ile yapılabilmektedir. Öz kaynak maliyetinin hesaplanması için SVFM de kullanılarak oluşturulan modelde, riskli varlıklar için beklenen getiriyi hesaplarken varlığı piyasa fiyatını kullanmaktadır. Ancak bu verilerin elde edilebilmesi için firmanın halka açılmış ve organize bir piyasada işlem görüyor olması zorunluluğu bulunmaktadır. Bu açıdan değerlendirildiğinde AOSM hesaplaması yapabilmek için ihtiyaç duyulan öz kaynak maliyetinin, halka açık olmayan firmalarda hesaplanabilmesi mümkün görünmemektedir. Diğer bir yandan, sağlıklı kararların alınabilmesi için piyasa temelli bilgilerin yanı sira finansal tablolarda yer alan bilgilerin de kullanılması ve bu iki bilgi türü arasındaki etkileşimin dikkate alınması da gerekmektedir (Ercan, vd. 2007). Tüm bu değerlendirmeler göz önüne alındığında "Muhasebe Betası" kavramı türetilmiştir. Muhasebe betası, döngüsel bir sektör ölçütü olarak ele alınabilmektedir. Sektörde faaliyet gösteren firmaların tamamının gelirlerindeki ve karlılıklarındaki dalgalanmalar ile firmanın gelirlerinde ve karlılığında gözlemlenen dalgalanmalar arasında bir etkileşimin bulunmaktadır. $\mathrm{Bu}$ etkileşimin boyutu da muhasebe betası kavramı ile ifade edilebilmektedir (Brealey \& Myers, 1996: 222). Kısaca, aynı sektörde ya da piyasada faaliyet gösteren firmaların muhasebe bilgileri ile sistematik riskleri arasındaki ilişki, birbirine benzer nitelik taşıma ihtimali yüksek görülmektedir. Bu nedenle, uzun yıllardır halka açı olmayan firmalar için sistematik riskin tespitinde aynı sektörde ya da piyasada faaliyet gösteren halka açık rakiplerinin muhasebe bilgilerinin kullanılması önerilmektedir. Hesaplamalar için tüm verileri bulunan halka açık firmalar kullanılarak tahmin edilecek modeller, halka açı olmayan rakiplerinin öz kaynak maliyetlerinin hesaplanmasinda kullanılabilmektedir.

Çalışmanın temel amacı, çimento sektöründe farklı ülkelerde faaliyet gösteren halka açık firmaların mali tablo verileri ile sistematik risk göstergesi olan finansal beta katsayıları arasındaki ilişkinin tespit edilmesidir. $\mathrm{Bu}$ amaç doğrultusunda Türkiye ve dünyadaki ana 
çimento üreticisi ülkelerde faaliyet gösteren firmaların karşılaştırılması hedeflenmektedir. Çalışma motivasyonu literatürde ilgili konu ile alakalı oldukça fazla çalışma bulunması ve bu çalışmaların önemli ölçüde farklı bulgular elde etmiş olmasıdır. Finansal beta katsayısı üzerinde etkili olan finansal oranların çimento sektörü açısından da ülkeler bazında farklılaşıp farklılaşmadığı üzerinde odaklanılmaktadır. Çalışmanın sonraki bölümlerinde, literatür araştırması, veri ve metodoloji tanıtılacak, analiz bulguları sunulduktan sonra çalışmanın sonucu tartışılacaktır.

\section{LITERATÜR ARAŞTIRMASI}

Finansal beta ve firmaların finansal oranları ilişkini araştırmış literatürde önemli sayıda çalışma bulunmaktadır. Yatııımcıların risk algılarının firmaların mali verileri ile ilişkisi konusu uzun yıllardır finans literatüründe gündemde olan bir konudur. Çalışmanın literatür taraması Tablo 1'de özetlenmektedir.

Konu ile ilişkili literatürün genel özellikleri incelendiğinde önemli bir nokta dikkat çekmektedir. Öncelikle Finansal beta katsayısı ile finansal oranların ilişkisi sektörlere, incelenen dönemlere ve incelenen ülkelere göre oldukça çeşitlidir. Bu çeşitlilik istatistiksel olarak anlamlı finansal oranlarda olduğu kadar, oranların regresyon katsayılarında ve işaretlerinde de görülmektedir. Teorik olarak beklenen bir durum olarak yorumlanan çeşitlilik, sektörden sektöre firma riskini etkileyen göstergelerin değişmesinden kaynakladığ sıkça yer bulmuştur.

\section{VERI VE METODOLOJI}

Çalışmanın amacına uygun olarak veriler Bloomberg Terminal veri tabanı yardımı ile elde edilmiştir. Analizde kullanılan veriler iki farklı set olarak oluşturulmuştur. İlk veri setinde Türkiye'de faaliyet gösteren çimento firmalarına ait değişkenler hazırlanırken; ikinci veri setinde Rusya, İtalya, İspanya, Almanya, Ukrayna, Fransa, Polonya, Yunanistan, Portekiz ve Birleşik Krallık piyasalarında faaliyet gösteren çimento firmalarına yer verilmiştir. Bu ülkelerde faaliyet gösteren çimento firmaları analiz aşamalarında "Diğer Ülkeler" rumuzu kullanılarak belirtilmiştir. Türkiye dışında adı geçen ülkelerin çalışmaya dahil edilmesindeki sebep, 2016 yılında Rekabet Kurulu tarafından yayımlanmış olan Çimento Sektör Araştırma raporunda 2013 y1lı Dünya çimento üretiminin \%65,51 oranında bu ülkelerde gerçekleştirilmiş olmasıdır. Diğer yandan Türkiye aynı raporda 2013 yılı dünya çimento üretiminin \%17,26'sını gerçekleştirmesi ile de ön plana çıkmaktadır. Analiz periyodu olarak son on yıllık çeyreklik veriler elde toplanmış ve 2007 yılı 4. çeyreğinden 2017 yılı 3. çeyreğine kadar 40 dönemlik iki veri seti oluşturulmuştur. 
The Journal of Accounting and Finance- January/2019

(81): 231- 248

Tablo 1: Finansal Beta Katsayısı ve Finansal Oranların İlișkisi Literatürü

\begin{tabular}{|c|c|c|c|c|c|c|}
\hline Künye & Ülke & Dönem & $\begin{array}{l}\text { Analiz } \\
\text { Tekniği }\end{array}$ & Sektör & Anlamlı Oranlar & Sonuçlar \\
\hline $\begin{array}{l}\text { Determinants of Market } \\
\text { Beta: The Impacts of Firm- } \\
\text { Specific Accounting Figures } \\
\text { and Market Conditions } \\
\text { Schlueter \& Sievers (2014) }\end{array}$ & $\mathrm{ABD}$ & 1990-1999 & Regresyon & $\begin{array}{l}\text { Center for } \\
\text { Research in } \\
\text { Security } \\
\text { Prices } \\
\text { (CRSP) }\end{array}$ & $\begin{array}{l}\text { Büyüme riski, yayılma riski, gelir riski, üretim riski, } \\
\text { finansal risk, operasyonel riskinin }\end{array}$ & $\begin{array}{l}\text { Analiz sonucu, anlamlı çıkan oranların Pazar betasının } \\
\text { belirlenmesinde faydalanılan muhasebe betası için çok önemli bir } \\
\text { rol oynadığı, gelecekte yapılacak çalışmalarda ABD dısıındaki } \\
\text { firmalar için bu oranların etkisinin araştırılması gerekliliği } \\
\text { vurgulanmıştır. }\end{array}$ \\
\hline $\begin{array}{l}\text { The Relationship Between } \\
\text { Accounting Beta and CAPM: } \\
\text { Evidence from Turkey } \\
\text { Er and Kaya (2012) } \\
\end{array}$ & Türkiye & $2007-2010$ & Regresyon & $\begin{array}{l}\text { Borsa } \\
\text { İstanbul }\end{array}$ & $\begin{array}{l}\text { Finansal Kaldıraç, Cari Oran, Faiz Karşılama Oranı, } \\
\text { Faaliyet Kaldıracı, Temettü Ödeme Oranı, Varlık } \\
\text { Büyüklüğ̈ü, Defter Değeri Piyasa Değeri Oranı, Büyüme }\end{array}$ & $\begin{array}{l}\text { Yapılan analiz sonucunda, yalnızca bir muhasebe değişkeninin, } \\
\text { İsletme Kaldıraç'ın, CAPM'nin beta ile ilişkilendirildiğini } \\
\text { gösterilmiştir. }\end{array}$ \\
\hline $\begin{array}{l}\text { Adjusted Accounting Beta, } \\
\text { Operating Leverage and } \\
\text { Financial Leverage as } \\
\text { Determinants of Market } \\
\text { Beta: A Synthesis and } \\
\text { Empirical Evaluation } \\
\text { Mensah (1992) } \\
\end{array}$ & $A B D$ & $\begin{array}{l}1966-1977 \\
1967-1986\end{array}$ & Regresyon & $\begin{array}{l}\text { Center for } \\
\text { Research in } \\
\text { Security } \\
\text { Prices } \\
\text { (CRSP) }\end{array}$ & $\begin{array}{l}\text { Net Gelirler, Operasyonlardan Sağlanan Fon Hareketleri, } \\
\text { Operasyonlardan İşletme Sermayesi, Operasyonlardan } \\
\text { Nakit Akışı. }\end{array}$ & $\begin{array}{l}\text { Getiriye ek olarak üç muhasebe akış ölçüsü, pazar riskini } \\
\text { tanımlamada en iyi modelin Mandelker ve Rhee model olduğunu } \\
\text { belirtmiş̧ir. }\end{array}$ \\
\hline $\begin{array}{l}\text { Accounting Information and } \\
\text { Market Beta } \\
\text { Amorim et al. (2014) }\end{array}$ & Brezilya & 1995-2013 & Regresyon & $\begin{array}{l}\text { BM\&F } \\
\text { Bovespa } \\
\text { Stock } \\
\text { Exchange }\end{array}$ & $\begin{array}{l}\text { END: Borçlanma; GIRO: Net İIsletme Sermayesi; LIQ: } \\
\text { Likidite; GAF: Finansal Kaldıraç Derecesi; GAO: } \\
\text { Operasyonel Kaldıraç Derecesi; ICJ: Faiz Kapsama Oranı }\end{array}$ & $\begin{array}{l}\text { Sonuç olarak vergi öncesi gelir, Şirket değeri, borç ve likidite ile } \\
\text { borsada işlem gören ve borsada işlem gören Brezilyalı şirketlerin } \\
\text { muhasebe ve piyasa betaları arasındaki ilişkiyi en iyi açıklayan } \\
\text { değişkenlerdir. }\end{array}$ \\
\hline $\begin{array}{l}\text { The Association Between } \\
\text { Market Determined and } \\
\text { Accounting Determined Risk } \\
\text { Measures } \\
\text { Beaver et al. (1970) }\end{array}$ & ABD & $\begin{array}{l}\text { 1947-1957, } \\
1956-1965\end{array}$ & Regresyon & $\begin{array}{l}\text { Center for } \\
\text { Research in } \\
\text { Security } \\
\text { Prices } \\
\text { (CRSP) }\end{array}$ & $\begin{array}{l}\text { Temettü Ödeme Oranı, Büyüme, Büyüklük, Kaldıraçlar, } \\
\text { Likidite Oranları, Gelir Değişkenliği }\end{array}$ & $\begin{array}{l}\text { Çalışma sayesinde muhasebe verileri ile risk hesaplamaları } \\
\text { arasındaki etkileşimle ilgili ek bilgiler sunacak ve yatırımcıların } \\
\text { kararları kolaylaştıracak şekilde muhasebe sisteminin } \\
\text { yapıllandırılmasına yönelik bir temel oluş̧urulmasına yardımcı } \\
\text { olacağı sonucuna varılmıştır. }\end{array}$ \\
\hline $\begin{array}{l}\text { Halka Açık Firmaların Beta } \\
\text { Katsayılarının Regresyon } \\
\text { Modeli Ile Tespiti Ve Halka } \\
\text { Açı Olmayan Firmalara } \\
\text { Yönelik Uygulanabilirliği } \\
\text { Ercan vd. (2007) }\end{array}$ & Türkiye & $2000-2005$ & $\begin{array}{l}\text { Regresyon, } \\
\text { Korelasyon }\end{array}$ & İMKB100 & $\begin{array}{l}\text { Cari Oran, Asit Test Oranı, Nakit Oranı, Stok Devir Hızı, } \\
\text { Alacak Devir Hızı, Varlık Dev. Hız, Top. Borç Oranı, } \\
\text { Aktif ve Satı̧ Logaritması, UV Borç Oranı, Faiz } \\
\text { Karşlama Oranı, Kar Marjı, Varlıkları Kazanma Gücü, } \\
\text { Öz Sermaye Kazanma Gücü, Öz Sermaye Çarpanı }\end{array}$ & $\begin{array}{l}\text { Tekstil sektörünün yoğunluk gösterdiği Türkiye' de halka açık } \\
\text { olmayan firmaların özsermaye maliyetlerini CAPM' a göre } \\
\text { hesaplamada kullanacakları betaların bu çalışmada tespit edilen } \\
\text { model ile güvenli bir biçimde yapılabileceği sonucuna varılmıştır. }\end{array}$ \\
\hline $\begin{array}{l}\text { Beta Katsayısını Etkileyen } \\
\text { Finansal Oranlar: Gida Ve } \\
\text { Makine İmalat Sektöründe } \\
\text { Bir Uygulama } \\
\text { Bekçioğlu vd. (2003) }\end{array}$ & Türkiye & 1999-2001 & Regresyon & $\begin{array}{l}\text { Makine } \\
\text { İmalat, Gıda }\end{array}$ & $\begin{array}{l}\text { Cari oran, Asit test oranı, Toplam borçların Öz Sermayeye } \\
\text { oranı, Faizleri Karşılama Oranı, Aktif karlılığı }\end{array}$ & $\begin{array}{l}\text { Beta katsayısı ile finansal oranlar arasındaki ilişkileri basamaklı } \\
\text { regresyon tekniği ile inceleyen çalışmada, anlamlı olarak tespit } \\
\text { edilen finansal oranların finansal beta katsayısını açıklama } \\
\text { gücünün } 0,35 \text { civarında olduğu sonucuna ulaşılmıştır. }\end{array}$ \\
\hline
\end{tabular}


Tablo 1: Finansal Beta Katsayısı ve Finansal Oranların İlişkisi Literatürü (Devamı)

\begin{tabular}{|c|c|c|c|c|c|c|}
\hline Künye & Ülke & Dönem & $\begin{array}{l}\text { Analiz } \\
\text { Tekniği }\end{array}$ & Sektör & Anlamlı Oranlar & Sonuçlar \\
\hline $\begin{array}{l}\text { Sistematik Riskin } \\
\text { Belirleyicileri: IMKB'de } \\
\text { Sektörel Karşılaştırma } \\
\text { Tanrı̈öven ve Aksoy (2011) }\end{array}$ & Türkiye & $1997-2008$ & Regresyon & İMKB 100 & $\begin{array}{l}\text { Uzun Vadeli Borç/Toplam Borç, Aktif Büyüme Oranı, } \\
\text { Maddi Duran Varlıklar/ Devamlı Sermaye, Esas Kar } \\
\text { Büyüme Oranı ,Toplam Borç//Toplam Aktif, Satış } \\
\text { Büyüme Oranı, Kısa Vadeli Borç/Piyasa Değeri, Net Kar } \\
\text { Büyüme Oranı, Uzun Vadeli Borç/Piyasa Değeri, } \\
\text { Toplam Borç Büyüme Oranı, Toplam Borç /Piyasa } \\
\text { Değeri, Öz Sermaye Getirisi, Cari Rasyo, Aktif Getirisi, } \\
\text { Faaliyet Kaldıraç Derecesi, Faiz Amortisman ve Vergi } \\
\text { Öncesi Kar Marjı F_K Fiyat Kazanç Oranı, Faiz ve Vergi } \\
\text { Öncesi Kar Marjı, Fiyat Nakit Akışı Oranı, Hisse Başı } \\
\text { Kar, Ar-Ge/Satışlar, Finansal Borç/ Öz Sermaye,Aktif } \\
\text { Büyüklüğg̈ (Logaritmik), Finansal Borç /Toplam Borç, } \\
\text { Satış Büyüklügüu (Logaritmik), Kısa Vadeli Borç/Toplam } \\
\text { Borç, Piyasa Değeri Büyüklüğüu (Logaritmik) }\end{array}$ & $\begin{array}{l}\text { Satış büyümesi, kaldıraç, toplam borç içerisindeki kısa vadeli } \\
\text { borcun oranı, aktif büyüklüğ̈u, ve uzun vadeli borcun toplam } \\
\text { borca oranı betayı pozitif yönde (aynı yönde) etkilerken fiyat } \\
\text { kazanç oranı, satış büyüklügüü, maddi duran varlıkların devamlı } \\
\text { sermayeye oranı, toplam borcun özsermayeye oranı betayı negatif } \\
\text { (ters yönlü) yönlü etkilediği sonucuna varılmıştır. }\end{array}$ \\
\hline $\begin{array}{l}\text { Beta Katsayısının Muhasebe } \\
\text { Verilerine Dayalı Risk } \\
\text { Ölçütleriyle } \\
\text { İlişkilendirilmesi: İMKB } \\
\text { Örneği } \\
\text { Ersoy vd. (2010) }\end{array}$ & Türkiye & $1998-2006$ & $\begin{array}{l}\text { Çoklu } \\
\text { Doğrusal } \\
\text { Regresyon }\end{array}$ & $\begin{array}{l}\text { İMKB-Tüm } \\
\text { endeks }\end{array}$ & $\begin{array}{l}\text { Finansal Kaldıraç, Aktif Büyüklüğü (log), Cari Oran, } \\
\text { Kazanç Değişkenliği, Kazanç Büyümesi, Kar Payı } \\
\text { Dağıtım Oranı, Kazançların Birlikte } \\
\text { Değişkenliği }\end{array}$ & $\begin{array}{l}\text { Şirketlerin muhasebe verilerine dayalı risk ölçütleri ile piyasa } \\
\text { verilerine dayalı beta katsayısı arasında, şirket büyüklüğ̈̈ ve cari } \\
\text { oran ile açıklanabilen, istatistiksel olarak anlamlı bir ilişki olduğu } \\
\text { sonucuna varılmıştır. }\end{array}$ \\
\hline $\begin{array}{l}\text { Halka Açık Olmayan Anonim } \\
\text { Şirketlerde Sistematik Risk } \\
\text { Ölçütü Beta Katsayısının } \\
\text { Tahmin Edilmesi } \\
\text { Tepeli (2017) }\end{array}$ & Türkiye & $\begin{array}{l}\text { 2011- } \\
2015 \text { (çeyrekli } \\
\text { k) }\end{array}$ & $\begin{array}{l}\text { Pearson } \\
\text { Korelasyon, } \\
\text { Regresyon }\end{array}$ & BİST Turizm & $\begin{array}{l}\text { Cari Oran, Asit Test Oran, Nakit Oranı, Stok Devir Hızı, } \\
\text { Alacak Devir Hızı, Varlık Devir Hızı, Toplam Borç } \\
\text { Oranı, UV Borç Oranı, Faiz Karşılama Oranı, Kar Marjı, } \\
\text { ROA, ROE, Öz Sermaye Carpanı, Aktifin Logaritması, } \\
\text { Satışların Logaritması, Aktif Büyüme Oranı }\end{array}$ & $\begin{array}{l}\text { Analiz sonucunda halka açık olmayan şirketin beta katsayısı } 0.676 \\
\text { olarak bulunmuştur. Bu da bize endeksin } \% 10 \text { arttığı bir dönemde } \\
\text { o hissenin } \% 6.76 \text { değer kazanmasının, endeksin } \% 10 \text { düştüğ̈̈ bir } \\
\text { dönemde ise o hissenin } \% 6.76 \text { düşmesinin beklendiğini } \\
\text { göstermektedir. }\end{array}$ \\
\hline $\begin{array}{l}\text { Finansal Başarısızlık } \\
\text { Tahmini Kısıtlı Veri İle } \\
\text { Mümkün Mü? Lojistik } \\
\text { Sektöründen Bir Örnek: Ran } \\
\text { Lojistik Hizmetleri A.Ş } \\
\text { Karaa (2016) }\end{array}$ & Türkiye & $\begin{array}{l}\text { 2009/9- } \\
2010 / 3(\text { çeyre } \\
\text { klik) }\end{array}$ & $\begin{array}{l}\text { Altman Z } \\
\text { Skoru }\end{array}$ & Lojistik & $\begin{array}{l}\text { Net Kar/Piyasa Değeri Oranını, Faaliyet Karı/Aktif } \\
\text { Toplamı, Faaliyet Karı/Piyasa Değerini, Aktif } \\
\text { Büyümesini, Birleşik Kaldıraç }\end{array}$ & $\begin{array}{l}\text { Muhasebe betaları ile başarısızlık riskinin öngörülmesi tek başına } \\
\text { yeterli olmamakla birlikte kritik dönemlerde sinyal kabul } \\
\text { edilebilecek işaretler verdiği sonucuna ulaşlmıştır. }\end{array}$ \\
\hline $\begin{array}{l}\text { Muhasebe Verilerine Dayalı } \\
\text { Risk Ölçümü İle Sistematik } \\
\text { Risk İlisskisi: Borsa } \\
\text { İstanbul'da Bir Uygulama } \\
\text { Kara (2016) }\end{array}$ & Türkiye & 2011-2015 & Regresyon & Bist-100 & $\begin{array}{l}\text { Kısa Vadeli Borç/Toplam Borç, Maddi Duran } \\
\text { Varlık/Uzun Vadeli Borç, Finansman Oranı, Stok Devir } \\
\text { Hızı, Net Kar/Toplam Aktif, Faaliyet Karı/ Net Satış, } \\
\text { Hisse Başına Kar }\end{array}$ & $\begin{array}{l}\text { Çalıssma sonucunda, Kısa Vadeli Borç/Toplam Borç, Maddi Duran } \\
\text { Varlık/Uzun Vadeli Borç, Finansman Oranı, Stok Devir Hızı, Net } \\
\text { Kar/Toplam Aktif, Faaliyet Karı/ Net Satış, Hisse Başına Kar’ın } \\
\text { sistematik risk ile iliş̧isi olduğu tespit edilmiştir. }\end{array}$ \\
\hline $\begin{array}{l}\text { Accounting variables and } \\
\text { systematic risk } \\
\text { Castagna and Matolcsy (1978) }\end{array}$ & Avusturalya & $\begin{array}{l}1967-1976 \\
(67-71,72- \\
76,67-76)\end{array}$ & $\begin{array}{l}\text { Korelasyon, } \\
\text { Regresyon }\end{array}$ & $\begin{array}{l}\text { Australian } \\
\text { Associated } \\
\text { Stock } \\
\text { Exchange }\end{array}$ & $\begin{array}{l}\text { Borç Öz Kaynak Oranı, Likit Oran, Cari Oran, Toplam } \\
\text { Borç - Toplam Varlık Oranı, Hisse Başına Getiri } \\
\text { Büyümesi }\end{array}$ & $\begin{array}{l}\text { Muhasebe değişkenleri ile beta arasında ilişki olduğu tespit } \\
\text { edilmiştir. Sistematik risk ile değişkenler arasındaki ilişkinin yönü } \\
\text { borç/öz kaynak, borç/toplam kaynak, borç/piyasa değeri, } \\
\text { FVÖK/toplam varlık, temettü/kar, hisse başına gelirdeki artış, aktif } \\
\text { büyüklüğ̈ünün logaritması ve işlem hacmi ile pozitif yönlü iken } \\
\text { diğer değişkenler ile negatif yönlü olarak tespit edilmiştir }\end{array}$ \\
\hline
\end{tabular}


The Journal of Accounting and Finance- January/2019

(81): $231-248$

Tablo 1: Finansal Beta Katsayısı ve Finansal Oranların İlişkisi Literatürü (Devamı)

\begin{tabular}{|c|c|c|c|c|c|c|}
\hline Künye & Ülke & Dönem & $\begin{array}{l}\text { Analiz } \\
\text { Tekniği }\end{array}$ & Sektör & Anlamlı Oranlar & Sonuçlar \\
\hline $\begin{array}{l}\text { On the relation of systematic } \\
\text { risk and accounting variable } \\
\text { Chiou and } \mathrm{Su}(2007)\end{array}$ & - & - & - & & $\begin{array}{l}\text { Toplam Gelirler, Satışlar, Büyüme, Defter Değeri, } \\
\text { Temettü, Faaliyet Kaldıracı Derecesi, Finansal Kaldıraç } \\
\text { Derecesi }\end{array}$ & $\begin{array}{l}\text { Pozitif satış büyümesine sahip firmalarda sistematik riskin belirli } \\
\text { bir seviyesi için faaliyet kaldıraç derecesi ile finansal kaldıraç } \\
\text { derecesi pozitif iliş̧ki tespit edilmiştir. }\end{array}$ \\
\hline $\begin{array}{l}\text { Estimating the Market Risk } \\
\text { for Nontraded Securities: An } \\
\text { Application to Canadian } \\
\text { Public Utilities } \\
\text { Berkowitz (1998) }\end{array}$ & Kanada & $1975-96$ & Regresyon & $\begin{array}{l}\text { TSE300 } \\
\text { Index(Canadi } \\
\text { an) (non- } \\
\text { traded } \\
\text { companies) }\end{array}$ & $\begin{array}{l}\text { Borç Öz Kaynak Oranı, Hisse Başına Getiri Standart } \\
\text { Sapması, ROE Standart Sapması, Toplam Varlık } \\
\text { Büyümesi, Kukla Değişkenler }\end{array}$ & $\begin{array}{l}\text { Analiz sonucunda sistematik riskin muhasebe verileri ile tahmin } \\
\text { edilebildiği ve sermaye maliyeti hesaplamalarında da } \\
\text { kullanılabileceği sonucuna varılmıştır. }\end{array}$ \\
\hline $\begin{array}{l}\text { Beta Katsayısı ile Finansal } \\
\text { Oranlar Arasındaki } \\
\text { İlişkilerin Ölçülmesi: } \\
\text { İstanbul Menkul Kıymetler } \\
\text { Borsası'nda Bir Uygulama } \\
\text { Akça (2008) }\end{array}$ & Türkiye & $2005-2007$ & $\begin{array}{l}\text { Korelasyon } \\
\text { ve Regresyon } \\
\text { Analizi }\end{array}$ & $\begin{array}{l}\text { İstanbul } \\
\text { Menkul } \\
\text { Kiymetler } \\
\text { Borsası'nda } \\
\text { (IMKB-100) }\end{array}$ & $\begin{array}{l}\text { Cari Oran, Asit Test Oranı, Nakit Oran, Toplam Borçların } \\
\text { Varlıklara Oranı, Toplam Borçların Öz Sermayeye Oranı, } \\
\text { Kısa Vadeli Borçların Toplam Borçlara Oranı, Faiz } \\
\text { Karşılama Oranı, Finansal Borçların Toplam Borçlara } \\
\text { Oranı, Finansal Borçları Öz Sermayeye Oranı, Aktif } \\
\text { Kârlılı̆ıı Oranı }\end{array}$ & $\begin{array}{l}\text { Analiz sonuçlarında beta katsayısını açılama dereceleri } \\
\text { beklenenden düşük olmakla birlikte, bazı finansal oranlar ile beta } \\
\text { katsayısı arasında anlamlı iliş̧iler tespit edilmiş̧ir. }\end{array}$ \\
\hline $\begin{array}{l}\text { Evidence on The Information } \\
\text { Content of Accounting } \\
\text { Numbers: } \\
\text { Accounting-Based and } \\
\text { Market-Based } \\
\text { Estimates of Systematic Risk } \\
\text { Gonedes (1973) }\end{array}$ & ABD & $\begin{array}{l}\text { Ocak 1946- } \\
\text { Haziran } 1968\end{array}$ & Regresyon & $\begin{array}{l}\text { Center for } \\
\text { Research in } \\
\text { Security } \\
\text { (Prices, } \\
\text { Economy- } \\
\text { Wide Index, } \\
\text { Industry } \\
\text { Index) }\end{array}$ & $\begin{array}{l}\text { Gelirler, Ekonomi Gelir Değişkeni, Sektör Gelir } \\
\text { Değişkeni, Toplam Varlıklar, Ekonomi Toplam Varlık } \\
\text { Değişkeni, Sektör Toplam Varlık Değişkeni }\end{array}$ & $\begin{array}{l}\text { Sonuçta belirli zaman periyodlarında pazar değerleri ile muhasebe } \\
\text { rakamları arasında sistematik bir iliş̧i olabileceği vurgulanmışır. }\end{array}$ \\
\hline
\end{tabular}


Analizin veri toplama aşaması başlarında literatürden elde edilen değişkenler taranmıştır. Bu tarama sonucunda ilk etapta 22 adet finansal oranın finansal beta ile ilişkisinin tespit edildiği görülmüştür. ${ }^{1}$ Ancak analizlerin hem Türkiye hem de diğer ülkeler açısından yapılacak olması veri uyumlaştırma kısıtını doğurmuştur. Zira bazı oranlar bir firma açısından hesaplanmış bulunurken, diğer firmalar açısından hesaplanmamış olduğu gözlenmiştir. Bu nedenle analiz birliği sağlanması açısından tüm firmalar için hesaplanmış bulunan finansal oranlar üzerinden devam edilmesi kararlaştırılmıştır. Bu aşamada analizlerde kullanılan 11 finansal oran ve hesaplanma açılamaları Tablo 2'de gösterilmektedir. Finansal oranların belirli bir ölçüde azaltılmasının ardından veri dizaynı aşamasında Diğer Ülkelerde faaliyet gösteren çimento firmalarının bir kısmının sağlıksız bir veri kalitesine sahip olduğu tespit edilmiştir. $\mathrm{Bu}$ nedenle detaylı bir inceleme sonucunda Diğer Ülkeler rumuzu taşıyan firmaların sayısı 6'ya kadar, Türkiye firmaları sayısı ise 16'ya düşürülmüştür. Diğer Ülke firmaları İtalya, İspanya, Almanya, Yunanistan ve Portekiz piyasalarında işlem görmektedir.

Tablo 2. Çalışmada kullanılan finansal oranlar ve hesaplama yöntemleri

\begin{tabular}{|c|c|}
\hline ORAN & HESAPLAMA YÖNTEMİ \\
\hline Öz Kaynak Karlılığı (ROE) & Pay sahipleri için Mevcut Gelir/ Ortalama öz sermaye miktar \\
\hline Aktif Karlılı̆̆ı (ROA) & Net KAR / Ortalama Aktif Miktarı \\
\hline Cari Oran $(\mathrm{CO})$ & Dönen Varlıklar/ Kısa Vadeli Borçlar \\
\hline Asit Test Oranı (ATO) & $\begin{array}{l}\text { (Nakit ve nakit benzerleri+ Kısa Dönem Yatırımlar + Alacaklar) / } \\
\text { Kısa Vadeli Borçlar } \\
\text { (Dönen Varlıklar- (Stoklar + Gelecek Yıllara Ait Gelirler + Diğer } \\
\text { Dönen Varlıklar) / Kısa Vadeli Borçlar) }\end{array}$ \\
\hline Nakit Oranı (NO) & $\begin{array}{l}\text { Nakit ve akit benzerleri+ hisse senetleri ve diğer kısa vadeli } \\
\text { yatırımlar/Kısa vadeli borçlar } \\
\text { (Hazır Değerler+ Menkul Kıymetler / Kısa Vadeli Yabancı } \\
\text { Kaynaklar) }\end{array}$ \\
\hline Varlık Devir Hızı (VDH) & $\begin{array}{l}\text { Net Satışlar(Yılık) / ((Toplam Aktif (Cari) + Toplam Aktif (Önceki } \\
\text { Dönem)/2) } \\
\text { (Net Satışlar/ Toplam Aktif) }\end{array}$ \\
\hline Toplam Borç Oranı (TBO) & Toplam Borç / Toplam Varlık \\
\hline Faaliyet Kar Marjı (FKM) & Faaliyet Geliri / Toplam Gelirler \\
\hline Net Kar Marji (NKM) & Net Gelir / Toplam Gelir \\
\hline Log Satış Gelirleri (LSATIS) & İlgili yılın toplam satış gelirlerinin doğal logaritması \\
\hline Log Aktif Toplam (LAKTIF) & İlgili yılın toplam varlıklarının doğal logaritması \\
\hline
\end{tabular}

Tablo 1'de yer alan değişkenlerin Türkiye ve Diğer Ülkeler veri setleri açısından tanımlayıc1 istatistiksel bilgilerine Tablo 3 ve Tablo 4'de yer verilmektedir.

\footnotetext{
${ }^{1}$ Bu oranlar şöyle sıralanmaktadır: ROE, ROA, Cari Oran, Asit Test Oranı, Nakit Oranı, Stok Devir Hızı, Alacak Devir Hızı, Varlık Devir Hızı, Toplam Borç Oranı, Faiz Karşılama Oranı, Uzun Vadeli Borç Oranı, Finansal Kaldıraç Derecesi, Faaliyet Kaldıraç Derecesi, Logaritmik Aktif Toplam, Logaritmik Satış Gelirleri, Brüt Kar Marjı, Net Kar Marjı, Faaliyet Kar Marjı, Logaritmik Piyasa Değeri, Piyasa Değeri Defter Değeri Oranı, Temettü Ödeme Oranı, Hisse Başı Kar
} 
Tablo 3. Türkiye'de faaliyet gösteren firmalara ait değişkenlere ilişkin tanımlayıcı istatistikler

\begin{tabular}{|l|c|c|c|c|c|}
\hline Değişken & Gözlem Sayısı & Ortalama & $\begin{array}{c}\text { Standart } \\
\text { Sapma }\end{array}$ & Minimum & Maksimum \\
\hline BETA & 640 & 0.7516 & 0.2451 & 0.1137 & 2.1867 \\
\hline ROE & 640 & 0.1232 & 0.1159 & -0.2482 & 0.5239 \\
\hline ROA & 640 & 0.0835 & 0.0851 & -0.1407 & 0.4205 \\
\hline CO & 640 & 2.5290 & 1.7239 & 0.1480 & 10.8644 \\
\hline ATO & 640 & 1.7604 & 1.2883 & 0.0385 & 8.6049 \\
\hline NO & 640 & 0.7893 & 1.0055 & 0.0011 & 8.0263 \\
\hline VDH & 640 & 0.6990 & 0.4120 & 0.0980 & 2.3371 \\
\hline TBO & 640 & 0.1161 & 0.1299 & 0.0000 & 0.7314 \\
\hline FKM & 640 & 0.1324 & 0.1563 & -0.7280 & 0.5506 \\
\hline NKM & 640 & 0.1155 & 0.1677 & -1.0250 & 0.7801 \\
\hline LSATIS & 640 & 1.6587 & 0.5920 & 0.2576 & 3.6307 \\
\hline LAKTIF & 640 & 2.4912 & 0.7348 & 1.3804 & 5.0171 \\
\hline
\end{tabular}

Tablo 4. Diğer ülkelerde faaliyet gösteren firmalara ait değişkenlere ilişkin tanımlayıcı istatistikler

\begin{tabular}{|l|c|c|c|c|c|}
\hline Değişken & Gözlem Sayısı & Ortalama & $\begin{array}{c}\text { Standart } \\
\text { Sapma }\end{array}$ & Minimum & Maksimum \\
\hline BETA & 240 & 0.8432 & 0.3149 & -0.2566 & 1.6533 \\
\hline ROE & 240 & -0.0856 & 0.0402 & -0.1517 & 0.1631 \\
\hline ROA & 240 & 0.0144 & 0.7548 & -5.2702 & 0.4857 \\
\hline CO & 240 & 1.4286 & 0.5252 & 0.5309 & 3.2915 \\
\hline ATO & 240 & 0.7912 & 0.3947 & 0.1414 & 2.1533 \\
\hline NO & 240 & 0.4479 & 0.2741 & 0.0313 & 1.3083 \\
\hline VDH & 240 & 0.4624 & 0.0703 & 0.2392 & 0.6958 \\
\hline TBO & 240 & 0.4019 & 0.1336 & 0.0000 & 0.9081 \\
\hline FKM & 240 & 0.0955 & 0.1252 & -0.8875 & 0.5991 \\
\hline NKM & 240 & 0.0167 & 0.1581 & -1.0966 & 0.9620 \\
\hline LSATIS & 240 & 3.0368 & 0.3915 & 1.7362 & 3.7810 \\
\hline LAKTIF & 240 & 3.9831 & 0.3646 & 3.4651 & 4.6312 \\
\hline
\end{tabular}

Araştırmada, verilerin hem zaman hem de birim boyutu olması sebebiyle analiz yöntemi olarak Panel Veri Analizi kullanılmıştır. Panel veri analizi teorisinde tahmin yapılabilmesi için birtakım varsayımların sağlanması öngörülmektedir. Bu varsayımların sağlandığını araştırmak için model tahminlerinden önce testler yapılması gerekmektedir. $\mathrm{Bu}$ amaçla öncelikle değişkenler arası korelasyonlar incelenmiş Tablo 5 ve 6'da gösterilmiştir. 
Tablo 5. Türkiye'de faaliyet gösteren firmalara ait finansal oranların korelasyon tablosu

\begin{tabular}{|l|c|c|c|c|c|c|c|c|c|c|c|}
\hline & ROE & ROA & CO & ATO & NO & VDH & TBO & FKM & NKM & LSATIS & LAKTIF \\
\hline ROE & 1.00 & & & & & & & & & & \\
\hline ROA & $\mathbf{0 . 9 4}$ & 1.00 & & & & & & & & & \\
\hline CO & 0.19 & 0.03 & 1.00 & & & & & & & & \\
\hline ATO & 0.22 & 0.06 & $\mathbf{0 . 9 6}$ & 1.00 & & & & & & & \\
\hline NO & 0.14 & 0.02 & $\mathbf{0 . 8 6}$ & $\mathbf{0 . 9 0}$ & 1.00 & & & & & & \\
\hline VDH & 0.02 & -0.04 & -0.05 & 0.03 & -0.16 & 1.00 & & & & & \\
\hline TBO & -0.15 & -0.05 & -0.44 & -0.41 & -0.27 & -0.33 & 1.00 & & & & \\
\hline FKM & 0.64 & 0.65 & -0.03 & 0.02 & -0.01 & -0.15 & 0.01 & 1.00 & & & \\
\hline NKM & 0.66 & 0.63 & 0.12 & 0.17 & 0.12 & -0.08 & -0.15 & $\mathbf{0 . 7 3}$ & 1.00 & & \\
\hline LSATIS & -0.04 & 0.17 & -0.39 & -0.43 & -0.32 & -0.31 & 0.14 & 0.29 & 0.09 & 1.00 & \\
\hline LAKTIF & -0.09 & 0.11 & -0.35 & -0.41 & -0.22 & -0.56 & 0.25 & 0.22 & 0.03 & $\mathbf{0 . 9 4}$ & 1.00 \\
\hline
\end{tabular}

Tablo 6.Diğer ülkelerde faaliyet gösteren firmalara ait finansal oranların korelasyon tablosu

\begin{tabular}{|l|c|c|c|c|c|c|c|c|c|c|c|}
\hline & ROE & ROA & CO & ATO & NO & VDH & TBO & FKM & NKM & LSATIS & LAKTIF \\
\hline ROE & 1.00 & & & & & & & & & & \\
\hline ROA & 0.45 & 1.00 & & & & & & & & & \\
\hline CO & 0.11 & 0.15 & 1.00 & & & & & & & & \\
\hline ATO & 0.13 & 0.17 & $\mathbf{0 . 8 6}$ & 1.00 & & & & & & & \\
\hline NO & -0.02 & 0.12 & $\mathbf{0 . 8 5}$ & $\mathbf{0 . 8 5}$ & 1.00 & & & & & & \\
\hline VDH & 0.58 & 0.18 & -0.06 & 0.02 & -0.23 & 1.00 & & & & & \\
\hline TBO & -0.47 & -0.21 & -0.32 & -0.35 & -0.11 & -0.20 & 1.00 & & & & \\
\hline FKM & 0.50 & 0.22 & 0.12 & 0.10 & 0.11 & 0.12 & -0.28 & 1.00 & & & \\
\hline NKM & 0.60 & 0.20 & 0.10 & 0.08 & 0.00 & 0.33 & -0.34 & $\mathbf{0 . 7 6}$ & 1.00 & & \\
\hline LSATIS & 0.00 & -0.12 & -0.35 & -0.24 & -0.36 & 0.38 & 0.03 & -0.10 & -0.02 & 1.00 & \\
\hline LAKTIF & -0.06 & -0.13 & -0.37 & -0.27 & -0.36 & 0.24 & 0.06 & -0.10 & -0.06 & $\mathbf{0 . 9 7}$ & 1.00 \\
\hline
\end{tabular}

Tablo 5 ve 6'da yer alan korelasyon verileri incelendiğinde, beklendiği üzere birkaç finansal oranın arasındaki korelasyonların yüksek çıktığı görülmüştür. Açıklayıcı değişkenler arası yüksek korelasyonun çoklu doğrusal bağlılık problemine neden olacağ 1 düşüncesi ile modeller oluşturulurken korelasyonların dikkate alınması gerekmektedir. Değişkenler arası korelasyonların incelenmesinin ardından finansal betayı açıklamak için kullanılacak fonksiyon Eşitlik 1'de gösterilmektedir.

Finansal Beta $a_{i t}=f\left(\right.$ Finansal Oran $\left.{ }_{i t}\right)=$

$f\left(R O E_{i t}, R O A_{i t} C^{\prime} O_{i t}, A T O_{i t}, N O_{i t}, V D H_{i t}, T B O_{i t}, F^{\prime} M_{i t}, N K M_{i t}, L S A T I S_{i t}, L A K T I F_{i t}\right)$

Eşitlik 1'de yer alan fonksiyon, model aşamasına dönüştürülmeden önce panel veri analizinin ilk varsayımı olan birim kök sınamaları gerçekleştirilmiştir. Birim kök sınamaları literatürde birinci ve ikinci nesil testler olarak ayrışmaktadır. Testler yatay kesit bağımlılığını dikkate almaları yönünden ayrılmaktadır ve serilerde yatay kesit bağımlılı̆̆ bulunması 
halinde ikinci nesil panel birim kök testlerinin kullanılması önerilmektedir. Ancak TorresReyna (2007) ve Baltagi (2005) çalışmalarında makro panel veri özelliği taşımayan serilerde ${ }^{2}$ yatay kesit bağımlılığı aramanın gereksiz olduğunu göstermişlerdir. Çalışma veri setinde 10 yıllık çeyreklik veriler kullanılması sebebiyle birinci nesil birim kök testlerinden Levin-LinChu Birim Kök Sınaması kullanılmıştır. Panel veri analizi tahmin aşamasından önce yapılması gereken diğer aşamalar ise modellerde otokorelasyon ve değişen varyans olup olmadığının araştırılması ve Hausman testinin uygulanmasıdır. Ancak yatay kesit bağımlılığında olduğu gibi Torres-Reyna (2007) ve Baltagi (2005) çalışmalarında makro panel veri özelliği taşımayan serilerde otokorelasyon sınamalarının yapılmasının gereksiz olduğunu belirtmişlerdir. Bu nedenle çalışmanın analiz aşamasında sadece değişen varyans probleminin varlığını araştırmak amacıyla Modified Wald Değişen Varyans Testi kullanmış ve Hausman testi uygulanmıştır.

Gerekli testlerin yapılmasının ardından panel veri analizi varsayımlarının geçerli olması durumunda model tahminine geçilecek, aksi durumda ise dirençli (robust) tahminci seçimi yapılması gerekecektir. Dirençli tahmincilerin seçimi amacıyla Baltagi (2005) ve Torres-Reyna (2007) 'nın çalışmalarından yararlanılmıştır.

\section{BULGULARIN YORUMU}

Çalışmanın amacı ve panel veri analizi metodolojisi gereği model tahminlerine geçmeden önce serilere panel birim kök sınaması yapılması gerekmektedir. $\mathrm{Bu}$ amaçla, literatürde yer alan birinci nesil birim kök sınamalarından Levin-Lin-Chu (2002) test istatistikleri Türkiye ve Diğer Ülke verileri açısından Tablo 7 ve Tablo 8'de gösterilmektedir.

Tablo 7: Türkiye Verileri Levin-Lin-Chu Birinci Nesil Panel Birim Kök Testi

\begin{tabular}{|l|c|c|}
\hline \multirow{2}{*}{ ROE } & \multicolumn{2}{|c|}{ Levin-Lin-Chu Test İstatistikleri } \\
\cline { 2 - 3 } ROA & Test İstatistiği & Olasilı Değeri \\
\hline CO & -4.1518 & $0.0000^{*}$ \\
\hline ATO & -2.9575 & $0.0016^{*}$ \\
\hline NO & -2.0973 & $0.0180^{* *}$ \\
\hline VDH & -2.5668 & $0.0051^{*}$ \\
\hline TBO & -1.4850 & $0.0688^{* * *}$ \\
\hline d(TBO) & -3.0822 & $0.0010^{*}$ \\
\hline d2(TBO) & 4.0338 & 1.0000 \\
\hline FKM & -0.2884 & 0.3865 \\
\hline NKM & -9.8668 & $0.0000^{*}$ \\
\hline LSATIS & -8.5103 & $0.0000^{*}$ \\
\hline LAKTIF & -10.1069 & $0.0000^{*}$ \\
\hline d(LAKTIF) & -6.3106 & $0.0000^{*}$ \\
\hline
\end{tabular}

\footnotetext{
${ }^{2}$ Bir veri setinin makro panel veri özelliği taşıması için zaman boyutunun 20-30 yıl aralığında ya da üstünde olmasi gerekmektedir (Baltagi, 2005).
} 
Tablo 8. Diğer Ülke Verileri Levin-Lin-Chu Birinci Nesil Panel Birim Kök Testi

\begin{tabular}{|l|c|c|}
\hline \multirow{2}{*}{\multicolumn{2}{|c|}{}} & \multicolumn{2}{c|}{ Levin-Lin-Chu Test İstatistikleri } \\
\cline { 2 - 3 } & Test İstatistiği & Olasilık Değeri \\
\hline ROA & -5.5809 & $0.0000^{*}$ \\
\hline CO & -6.1021 & $0.0000^{*}$ \\
\hline d(CO) & -0.8681 & 0.1927 \\
\hline ATO & -8.6900 & $0.0000^{*}$ \\
\hline d(ATO) & -0.8819 & 0.1889 \\
\hline NO & -8.3195 & $0.0000^{*}$ \\
\hline d(NO) & -0.6868 & 0.2461 \\
\hline VDH & -9.8742 & $0.0000^{*}$ \\
\hline TBO & -2.9967 & $0.0014^{*}$ \\
\hline d(TBO) & 0.3243 & 0.6272 \\
\hline FKM & -7.8372 & 0.0000 \\
\hline NKM & -9.1177 & $0.0000^{*}$ \\
\hline LSATIS & -8.2212 & $0.0000^{*}$ \\
\hline LAKTIF & -3.1086 & $0.0009^{*}$ \\
\hline d(LAKTIF) & 0.4485 & 0.6731 \\
\hline
\end{tabular}

Tablo 7'de yer alan birim kök sınaması sonuçlarına göre, Türkiye verilerinde Toplam Borç Oranı ve Logaritmik Aktif Toplam dışındaki tüm seriler düzeyde durağan olarak belirlenmiştir. Toplam Borç Oranı ikinci farkı alındığında, Logaritmik Aktif Toplam ise birinci fark1 alındığında durağan hale gelmektedir. Tablo 7'de yer alan birim kök sınamas1 sonuçlarına göre, diğer ülke verilerinde ise Cari Oran, Asit Test Oranı, Nakit Oran, Toplam Borç Oranı ve Logaritmik Aktif Toplam dışındaki tüm seriler düzeyde durağan olarak belirlenmiştir. Bahsi geçen oranlar birinci farkları alındığında durağan hale gelmektedir. Korelasyon matrisi ve birim kök sınamaları sonrasında tahmin edilecek modeller Eşitlik 2 ve 3 'te gösterilmektedir.

$$
\begin{aligned}
& \text { Türkiye }-\beta e t a_{i t}=\theta_{0}+\theta_{1} R O A_{i t}+\theta_{2} C_{i t}+\theta_{3} V D H_{i t}+\theta_{4} d 2 T B O_{i t}+\theta_{5} F K M_{i t}+ \\
& \theta_{6} \text { LSATIS }_{i t}+\varepsilon_{i t} \\
& \text { DỦlke }-\beta e t a_{i t}=\theta_{0}+\theta_{1} R O A_{i t}+\theta_{2} d C_{i t}+\theta_{3} V D H_{i t}+\theta_{4} d T B O_{i t}+\theta_{5} F K M_{i t}+ \\
& \theta_{6} \text { LSATIS }_{i t}+\varepsilon_{i t}
\end{aligned}
$$

Modellerin tespit edilmesinin ardından Hausman testi uygulanmıştır. (Baltagi, 2005). Hausman testine ait sonuçlar Tablo 9'de özetlenmektedir. 
Tablo 9. Hausman Test İstatistikleri

\begin{tabular}{|l|c|c|}
\hline \multirow{2}{*}{} & \multicolumn{2}{|c|}{ Hausman Test İstatistikleri } \\
\cline { 2 - 3 } & $\chi^{2}$ Değeri & Olasılık Değeri \\
\hline Eşitlik 2 & 47.18 & $0.0000^{*}$ \\
\hline Eşitlik 3 & 29.01 & $0.0000^{*}$ \\
\hline
\end{tabular}

Yapılacak analizlerde kullanılacak olan panel veri modellerine ilişkin Hausman test istatistikleri Tablo 9'da yer almaktadır. Test istatistiğine göre Eşitlik 2'deki Türkiye firmalarına ait modelde ve Eşitlik 3'teki diğer ülke firmalarına ait modelde sıfır hipotezi reddedilmektedir. Bunun anlamı hata terimleri ile açıklayıcı değişkenler arasında ilişkinin olduğu dolayısıyla da alternatif hipotez altında rassal etkiler tahmincisinin tutarsiz, ancak sabit etkiler tahmincisinin tutarlı olduğudur.

Panel veri analizi testlerinden bir diğeri ise değişen varyans testleridir. Literatürde değişen varyans sınaması yapan birçok test bulunmaktadır ve çalışma için Modified Wald Değişen Varyans Testi seçilmiştir. Değişen varyans testine ait sonuçlar Tablo 10'da özetlenmektedir.

Tablo 10. Modified Wald Değişen Varyans Test İstatistikleri

\begin{tabular}{|l|c|c|}
\hline \multirow{2}{*}{} & \multicolumn{2}{|c|}{ Modified Wald Değişen Varyans Test İstatistikleri } \\
\cline { 2 - 3 } & $\chi^{\mathbf{2}}$ Değeri & Olasılık Değeri \\
\hline Eşitlik 2 & 351.27 & $0.0000^{*}$ \\
\hline Eşitlik 3 & 18.93 & $0.0043^{*}$ \\
\hline
\end{tabular}

Tablo 10'da belirlenen modellere ilişkin değişen varyans test istatistikleri yer almaktadır. Sonuçlar incelendiğinde Eşitlik 2'de ve Eşitlik 3'te yer alan model için \%1 anlamlılık düzeyinde değişen varyans olduğuna karar verilmektedir. Modellerde değişen varyans probleminin olması sebebiyle Torres-Reyna (2007) 'nın önerdiği dirençli (robust) model tahmini yapılmıştır. Model tahmin sonuçlarında istatistiksel olarak anlamsız değişkenler elenmiştir ve tahmin sonuçları Tablo 11 ve Tablo 12'de gösterilmektedir.

Tablo 11. Türkiye Modeli Tahmin Sonuçları

\begin{tabular}{|l|l|l|l|l|}
\hline Bağımlı Değişken & Beta Katsayısı & Firma Sayısı & 16 & \\
\hline Dönem & $2007 C ̧ 4-2017 C ̧ 3$ & Dönem Sayısı & 40 & \\
\hline Gözlem Sayısı & 640 & & & \\
\hline $\mathbf{R}^{2}$ & 0.2632 & & & \\
\hline \hline $\begin{array}{l}\text { Açıklayıcı } \\
\text { Değişkenler }\end{array}$ & Katsayılar & $\begin{array}{l}\text { Std. Hata } \\
\text { (Dirençli) }\end{array}$ & t Değeri & $\begin{array}{l}\text { Olasılık } \\
\text { Değeri (p) }\end{array}$ \\
\hline ROE & 0.6258908 & 0.1468053 & 4.26 & $0.001^{*}$ \\
\hline CO & -0.011595 & 0.0051356 & -2.26 & $0.039^{* *}$ \\
\hline VDH & -0.442728 & 0.0753059 & -5.88 & $0.000^{*}$ \\
\hline FKM & 0.1395152 & 0.0692451 & 2.01 & $0.062^{* * *}$ \\
\hline LAKTIF & -0.4029738 & 0.0916352 & -4.40 & $0.001^{*}$ \\
\hline SABIT TERİM & 1.998703 & 0.2477709 & 8.07 & $0.000^{*}$ \\
\hline
\end{tabular}


Tablo 12. Diğer Ülkeler Modeli Tahmin Sonuçları

\begin{tabular}{|l|l|l|l|l|}
\hline Bağımlı Değişken & Beta Katsayıs1 & Firma Sayısı & 6 & \\
\hline Dönem & $2007 C ̧ 4-2017 C ̧ 3$ & Dönem Sayısı & 40 & \\
\hline Gözlem Sayısı & 240 & & & \\
\hline $\mathbf{R}^{2}$ & 0.5599 & & & \\
\hline \hline $\begin{array}{l}\text { Açıklayıcı } \\
\text { Değişkenler }\end{array}$ & Katsayılar & Std. Hata & t Değeri & $\begin{array}{l}\text { Olasılık } \\
\text { Değeri (p) }\end{array}$ \\
\hline ROE & -0.0529257 & .0174873 & -3.03 & $0.029^{* *}$ \\
\hline LSATIŞ & 0.454306 & .142139 & 3.20 & $0.024^{* *}$ \\
\hline SABIT TERंM & -0.5409892 & .4325668 & -1.25 & 0.266 \\
\hline
\end{tabular}

Dirençli tahminci kullanılarak modellerin tahmin edilmesinin ardından ulaşılan anlamlı modeller Eşitlik 4 ve 5'te gösterilmektedir.

$$
\begin{aligned}
& \text { Türkiye }-\beta e t a_{i t}=1.9987+0.6259 R^{2} E_{i t}-0.0116 \mathrm{CO}_{i t}-0.4427 \mathrm{VDH}_{i t}+ \\
& 0.1395 \mathrm{FM}_{i t}-0.4029 \text { LAKTIF }_{i t}
\end{aligned}
$$

$$
\text { DỦlke }-\beta e t a_{i t}=-0.5410-0.0529 R O A_{i t}+0.4543 \text { LSATIS }_{i t}
$$

Model tahminlerinden elde edilen sonuçlara göre Türkiye'de faaliyet gösteren çimento firmalarının sistematik risklerini ifade eden finansal beta katsayıları, öz kaynak karlılığı, cari oran, varlık devir hızı, faaliyet kar marjı ve logaritmik aktif büyüklüğü değişkenleri ile istatistiksel olarak anlamlı bir ilişki içerisindedir. Elde edilen bu sonuç Ercan vd. (2007), Bekçioğlu, vd. (2003) ve Tepeli (2017) çalışmaları ile paralellik arz etmektedir. Buna göre, öz kaynak karlılığında meydana gelecek olan bir birimlik bir artış çimento firmalarının beta katsayısını 0.6259 birim arttırırken, faaliyet karında meydana gelen bir birimlik artış ise 0.1395 birim arttırmaktadır. Diğer yandan firmaların cari oranlarında meydana gelecek bir birimlik artış finansal beta katsayısını 0.0116 birim, varlık devir hızında meydana gelecek bir birimlik artış 0.4427 birim, aktif büyüklüğünde meydana gelecek bir birimlik artış ise 0.4029 birim azaltmaktadır. Çimento firmaları sabit giderleri yüksek, stoklama imkanı ise kısıtlı olan firmalardır. Bu nedenle risklerinin ellerindeki varlıklarla ilişkili olması çalışmanın beklenen bir sonucudur. Bu firmalar için cari oranın yüksek olması, daha çok hazır değerlerin yüksekliği ve çalışma sermayesi ile ilişskilendirilebilir. Diğer yandan yüksek yatırım tutarları içeren varlıklarını ne kadar verimli kullandığı da risk üzerinde önemli ölçüde etki görülmektedir. Firmaların çalışma sermayelerinin, varlık devir hızlarının ve aktif büyüklüklerinin yükselmesi sistematik riskleri üzerinde negatif etki yapması teorik olarak beklenen bir durum olarak görülmektedir. Diğer yandan öz kaynak karlılığ 1 ve faaliyet kar marjının risk üzerinde arttırıcı bir etkiye sahip olması beklenen bir sonuç olarak görülmemektedir. Her iki değişkenin de karlılık içermesi dikkatleri tanımlayıcı istatistikler üzerine yöneltmektedir. \%13,24 ortalama faaliyet kar marj1 ve \%11,54 ortalama net kar marj1 ile Türkiye'de faaliyet gösteren çimento firmaları uluslar arası alandaki rakiplerine göre oldukça yüksek karlar elde etmektedir. Ancak bu karlılıklarını standart sapmalarına dikkat edilecek olursa yaklaşık \%16-17 aralığında yüksek bir dalgalanmaya sahip olduğu görülmektedir. Karlılık değişkenlerinin sistematik risk üzerinde arttırıcı bir etkiye sahip olmasının firmaların karlılıklarının dalgalı bir yapıya sahip olmasından kaynaklandığı düşünülmektedir. 
Tahmin sonuçları Diğer Ülkelerde faaliyet gösteren çimento firmalarının sistematik riskleri açısından incelendiğinde ise iki değişken istatistiksel olarak anlamlı bulunmuştur. Aktif karlılığı ve logaritmik satış büyüklüğü değişkenlerinin anlamlı bulunması Chiou \& Su (2007) ve Tanrı̈ven ve Aksoy (2011) çalışmaları ile paralellik arz etmektedir. Bu grupta yer alan çimento firmalarının farklı ülkelerden olması ve farklı dinamiklere sahip olması istatistiksel olarak anlamlı değişken sayısındaki düşüşün bir nedeni olarak düşünülmektedir. Sonuçlar incelendiğinde, aktif karlılığındaki bir birimlik artışın sistematik risk üzerinde 0.0529 birimlik bir düşüşe neden olurken, satış büyüklüğündeki bir birimlik artışın 0.4543 birimlik bir artışa neden olduğu görülmektedir. Sabit yatırımları yüksek tutarda olan çimento firmalarının aktif karlılıklarını arttırmalarının sistematik risk üzerine olan etkisinin negatif ve anlamlı olması teorik olarak beklentiye uygun bir durumdur. Firmaların sahip oldukları varlıkları karlı kullanmaları yatırımcıların algıladığı risk algısında bir düşüşe sebep olmaktadır. Diğer yandan satış büyüklüğünün sistematik risk üzerinde pozitif bir etkiye sahip olması, tek başına açıklanması mümkün olamayacak bir sonuç oluşturmaktadır. Satışların artmasının, firmaların alacak tahsil risklerini arttırmanın yanında, yatırımcılarda ne kadar karlı satış yapıldığına dair bir risk algısı oluşturmaktadır. Tablo 4'de yer alan tanımlayıcı istatistikler incelendiğinde ortalama \%1,6 net kar marjı ile çalışmakta olan diğer ülke çimento firmalarında, yüksek satışın, yüksek risk algısı oluşturması açıklanabilir bir sonuç olarak görülmektedir.

Analizlerden elde edilen sonuçlar çalışma motivasyonu açısından da değerlendirilebilir. Çimento sektöründe faaliyet gösteren halka açık firmaların sistematik riskleri Türkiye ve Diğer Ülkeler açısından, aynen literatürde olduğu gibi, farklı mali tablo değişkenlerinden etkilenmektedir. Araştırmada çimento sektörü açısından literatürde yer alan çalışmalarla aynı doğrultuda sonuçlar elde edilmiştir.

\section{SONUÇ}

Halka açık firmalarda olduğu gibi halka açık olmayan firmalarda da ortaklar karşılaşabilecekleri riskleri bilmek ve ona göre pozisyon almak istemektedir. Ancak halka açık olmayan firmalar için birçok piyasa verisinin hesaplanmıyor ya da hesaplanamıyor olması, karşı karşıya olunan risk düzeyi hakkında ilgili taraflara sağlıklı bilgi sağlayamamaktadır. Bu noktada hakla açık olmayan firmalara yatırım yapacak olan yatırımcıların ve firma yöneticilerinin kullanabileceği en etkin yöntemlerden biri muhasebe betalarıdır. Bu yöntem yatırımcıya ve yöneticilere söz konusu firma, halka açık bir firma olmasa da betanın tespit edebilme ve buna bağlı olarak da üstlenilen kaynak maliyetini hesaplayabilme olanağı sunmaktadır.

Çalışmanın temel amacı, çimento sektöründe faaliyet gösteren halka açık firmaların mali tablo verileri ile sistematik risk göstergesi olan finansal beta katsayıları arasındaki ilişkinin tespit edilmesidir. Çalışma motivasyonu, literatürde ilgili konu ile alakalı hatırı sayılır derecede çalışma bulunması ve bu çalışmaların önemli ölçüde farklı bulgular elde etmiş olmasıdır. Finansal beta katsayısı üzerinde etkili olan finansal oranların çimento sektörü açısından da ülkeler bazında farklılaşıp farklılaşmadığı üzerinde odaklanılmaktadır. Çalışmada, Türkiye'de halka açık şekilde işlem gören ve çimento sektöründe faaliyet gösteren için 16 firma ile İtalya, İspanya, Almanya, Yunanistan ve Portekiz borsalarında işlem gören 6 firma için muhasebe betalarına etki eden oranlar hesaplanmıştır. Yapılan analizlerde Türkiye'de faaliyet gösteren halka açık çimento firması sayısının, Diğer Ülkeler grubundan 
yüksek olması çalışmanın zayıf yönünü oluşturan bir veri durumudur. Ancak Dünya Çimento Sektörünün ele alındığı Rekabet Kurulu Raporu incelendiğinde Türkiye, dünya çimento üretiminin \%17,26'sını tek başına gerçekleştirerek sektörde lider konumda yer almaktadır.

Analizlerde veri yapısı nedeniyle Panel Veri Analizi tercih edilmiş ve öncelikle metodolojik varsayımlar sınanmıştır. Model tahminleri sonucunda elde edilen ilk bulgular, Türkiye'de ve Diğer Ülkeler grubunda, beta üzerinde istatistiksel olarak anlamlı etkisi bulunan muhasebe değişkenleri farklılaşmaktadır. Farklı sektörlerde farklı finansal oranların ya da muhasebe değişkenlerinin beta üzerinde etkisinin bulunması literatürde sıklıkla tespit edilmiş bir durumdur. Ancak aynı sektör için farklı ülkeler bazında modellerin farklılaşması yönünden yapılan analizler özgünlük taşımaktadır. Tahmin edilen modellerde Türkiye'de işlem gören çimento firmaları için finansal beta ile istatistiksel olarak anlamlı ilişki bulunan oranlar Öz Kaynak Karlılığı, Cari Oran, Faaliyet Kar Marjı ve Logaritmik Aktif değişkenleri iken Diğer Ülkeler grubunda yer alan çimento firmaları için finansal beta ile istatistiksel olarak anlamlı ilişki bulunan oranlar Aktif Karlılığı ve Logaritmik Satış değişkenleridir.

Bulgular Türkiye açısından değerlendirildiğinde, çimento firmaları varlık yapılarının beta üzerinde önemli etkisi olduğu görülmektedir. Sabit giderleri yüksek ve stoklama imkanları kısıtlı olan çimento firmalarının riskleri ile çalışma sermayelerinin ilişkili olması teorik olarak beklenen bir sonuçtur. Firmaların çalışma sermayelerinin, varlık devir hızlarının ve aktif büyüklüklerinin yükselmesi sistematik riskleri üzerinde negatif etki yapmaktadır. Diğer yandan öz kaynak karlılığı ve faaliyet kar marjının risk üzerinde arttırıcı bir etkiye sahip olması beklenen bir sonuç olarak görülmemektedir. Her iki değişkenin de karlılık içermesi dikkatleri tanımlayıcı istatistikler üzerine yöneltmektedir. Türkiye'de faaliyet gösteren çimento firmaları uluslararası alandaki rakiplerine göre oldukça yüksek kar oranları ile çalışmaktadır. Ancak bu kar değişkenlerinin standart sapmalarına dikkat edilecek olursa, \%16-17 aralığında yüksek bir dalgalanmaya sahip olduğu görülmektedir. Karlılık değişkenlerinin sistematik risk üzerinde arttırıcı bir etkiye sahip olmasının firmaların karlılıklarının dalgalı bir yapıya sahip olmasından kaynaklandığı düşünülmektedir. Diğer ülkeler açısından bulgular incelendiğinde ise, öncelikle Türkiye firmalarına göre çok daha az değişken ile muhasebe değişkenlerinin ilişki olduğu görülmektedir. Bu grupta yer alan çimento firmalarının farklı ülkelerden olması ve farklı dinamiklere sahip olması istatistiksel olarak anlamlı değişken sayısındaki düşüşün bir nedeni olarak düşünülmektedir. İlk bulgular, sabit yatırımları yüksek tutarda olan çimento firmalarının, aktif karlılıklarını arttırmalarının sistematik risk üzerine negatif bir etkisi olduğunu göstermektedir. Bu durum teorik beklentiye uygun olarak görülmektedir. Diğer yandan satış büyüklüğünün sistematik risk üzerinde pozitif bir etkiye sahip olması, tek başına açıklanması mümkün olamayacak bir sonuç oluşturmaktadır. Satışların artmasının, firmaların alacak tahsil risklerini arttırmanın yanında, yatırımcılarda ne kadar karlı satış yapıldığına dair bir risk algısı oluşturmaktadır. Diğer Ülkeler için tanımlayıcı istatistikler incelendiğinde, ortalama \%1,6 net kar marjı ile çalışmakta olan diğer ülke çimento firmalarında, yüksek satışın yüksek risk algısı oluşturması, düşük karlılık sebebiyle açıklanabilir bir sonuç olarak görülmektedir.

Çalışmanın literatüre katkısı, Türkiye'de ya da uluslararası çimento sektöründe faaliyet gösteren halka açık olmayan bir firma için yatırımcıların ve ortakların istatistiksel olarak anlamlı bulunan muhasebe değişkenlerini kullanarak muhasebe betasını hesaplayabilecek olmalarıdır. Böylece yöneticiler maruz kalabilecekleri kaynak maliyeti riskini bilimsel bir şekilde tespit edebilecek, yatırımcılar karşılaşacakları riskleri 
ölçümleyerek rasyonel davranabilecektir. Diğer yandan muhasebe betası tespit etmek için farklı sektörlerde yer alan firmalar için farklı muhasebe betası modellemelerinin yapılması ve geliştirilmesi gerekliliği, bu alanda yapılmış birçok araştırmada da ortaya konulmuştur. $\mathrm{Bu}$ nedenle, yapılan analizlerin farklı sektörler için tekrarlanarak geliştirilmesi gelecek çalışmaların vizyonu olarak düşünülmektedir.

\section{KAYNAKLAR}

Akça S. (2008) "Beta Katsayısı İle Finansal Oranlar Arasındaki İlişkilerin Ölçülmesi: İstanbul Menkul Kıymetler Borsası'nda Bir Uygulama" Yayımlanmamış Yüksek Lisans Tezi, Adnan Menderes Üniversitesi Sosyal Bilimler Enstitüsü İşletme Ana Bilim Dalı İşletme Bölümü, Aydın.

Amorim, A. L. G. C.- Lima, I. S. - Pimeta Jr. T. (2014) "Accounting Information and Market Beta” Revista Universo Contábil, Blumenau, 10(4),pp. 128-143.

Baltagi, B. H. (2005). Econometric Analysis of Panel Data, 3rd Edition, John Wiley\&Sons Ltd., England.

Beaver, W.- Kettle, P. - Scholes, M. (1970) "The Association Between Market Determined and Accounting Determined Risk Measures" The Accounting Review, 45, pp.654-682.

Bekçioğlu S.- Öztürk M. - Kaderli Y. (2003) "Beta Katsayılarını Etkileyen Finansal Oranlar Gıda Ve Makine İmalat Sektöründe Bir Uygulama" Muhasebe ve Denetime Bakış Dergisi, Sayı:10.

Berkowitz, M. K. (1998) "Estimating the Market Risk for Nontraded Securities: An Application to Canadian Public Utilities" International Review of Financial Analysis, 7(2), pp. 171-179.

Brealey, R. A. - Myers, S. C. (1996), Principles of Corporate Finance, The McGraw-Hill Companies, Inc., New York.

Castagna, A. D. - Matolcsy, Z. P. (1978) "The Relationship Between Accounting Variables and Systematic Risk and the Prediction of Systematic Risk" Australian Journal of Management, 3(2), pp.113-126.

Chiou, C. C. - Su, R. K. (2007) "On the Relation of Systematic Risk and Accounting Variables” Managerial Finance, 33(8), pp.517-533.

Er, H. - Kaya İ. (2012) "The Relationship Between Accounting Beta And CAPM: Evidence from Turkey” International Journal of Social Sciences and Humanity Studies, 4(2), pp.233-243.

Ercan M. K.- Öztürk B. M.- Küçükkaplan İ. - Başçı E. S. (2007) "Halka Açık Firmaların Beta Katsayılarının Regresyon Modeli ile Tespiti ve Halka Açık Olmayan Firmalara Yönelik Uygulanabilirliğii” Dokuz Eylül Üniversitesi İktisadi ve İdari Bilimler Fakültesi Dergisi, 22(2), pp. 295-324. 
Ersoy, A.- Bozcuk, A. E. - Suntur, N. (2010) "Beta Katsayısının Muhasebe Verilerine Dayalı Risk Ölçütleriyle İlişkilendirilmesi: İMKB Örneği” Journal of Accounting \& Finance, 45, ss. 48-54.

Gonedes, N. J. (1973) "Evidence on the Information Content of Accounting Numbers: Accounting-based and Market-based Estimates of Systematic Risk" Journal of Financial and Quantitative Analysis, 8(3), pp.407-443.

Kara S. (2016) "Muhasebe Verilerine Dayalı Risk Ölçümü İle Sistematik Risk İlişkisi: Borsa İstanbul'da Bir Uygulama" Uluslararası Yönetim İktisat ve İşletme Dergisi, ICAFR-16 Özel Sayıs1, ss. 369-381.

Karaa İ. E. (2016) "Finansal Başarısızlık Tahmini Kısıtlı Veri İle Mümkün Mü? Lojistik Sektöründen Bir Örnek: Ran Lojistik Hizmetleri A.Ş.” International Journal of Human Sciences, 3(3), ss. 4357-4369.

Karels, G. V. - Sackley, W.H. (1993) "The Relationship Between Market and Accounting Betas for Commercial Banks" Review of Financial Economics, 2(2):59-72.

Levin, A. - Lin, C.H. - Chu, J. (2002) "Unit Root Tests in Panel Data: Asymptotic and Finite Sample Properties" Journal of Econometrics, 108(1), pp.1-24.

Mensah, Y. M. (1992) "Adjusted Accounting Beta, Operating Leverage and Financial Leverage as Determinants of Market Beta: A Synthesis and Empirical Evaluation" Review of Quantitative Finance and Accounting, 2(2), pp.187-203.

Schlueter, T. - Sievers, S. (2014) "Determinants of Market Beta: The Impacts of FirmSpecific Accounting Figures and Market Conditions" Review of Quantitative Finance and Accounting, 42(3), pp. 535-570.

Tanrı̈̈ven C. - Aksoy E. E. (2011) “Sistematik Riskin Belirleyicileri: İMKB'de Sektörel Karşılaştırma” MUFAD Muhasebe Finansman Dergisi, Say1: 51, ss. 119-138.

Tepeli Y. (2017) "Halka Açık Olmayan Anonim Şirketlerde Sistematik Risk Ölçütü Beta Katsayısının Tahmin Edilmesi: Turizm Sektörü Uygulaması" MUFAD Muhasebe Finansman Dergisi, Sayı:75, ss. 155-170.

Torres-Reyna, O. (2007) "Panel Data Analysis; Fixed and Random Effects using Stata" https://www.princeton.edu/ otorres/Panel101.pdf (01.02.2018).

Rekabet Kurulu Raporu Çimento Sektör Araştırması (2016), http://www.ekonomiraporu.com/uploads/2017_05_10_13_00_29_diyezmedia_doku man_Rekabet_Kurumu_-

_Cimento_Sektor_Raporu_Haziran_2016e5b5fdd4f4e0fcdf86a05dd68116b172.pdf (14.01.2018). 
(81): 231- 248 